University of Nebraska - Lincoln

DigitalCommons@University of Nebraska - Lincoln

\title{
Imagery rescripting and exposure group treatment of posttraumatic nightmares in Veterans with PTSD
}

\author{
Mary E. Long \\ Michael E. DeBakey Veterans Affairs Medical Center \\ Mary E. Hammons \\ Michael E. DeBakey Veterans Affairs Medical Center \\ Joanne L. Davis \\ University of Tulsa \\ B. Christopher Frueh \\ Baylor College of Medicine \\ Myrna M. Khan \\ Michael E. DeBakey Veterans Affairs Medical Center \\ See next page for additional authors
}

Follow this and additional works at: https://digitalcommons.unl.edu/publichealthresources

Part of the Public Health Commons

Long, Mary E.; Hammons, Mary E.; Davis, Joanne L.; Frueh, B. Christopher; Khan, Myrna M.; Elhai, Jon D.; and Teng, Ellen J., "Imagery rescripting and exposure group treatment of posttraumatic nightmares in Veterans with PTSD" (2011). Public Health Resources. 182.

https://digitalcommons.unl.edu/publichealthresources/182

This Article is brought to you for free and open access by the Public Health Resources at DigitalCommons@University of Nebraska - Lincoln. It has been accepted for inclusion in Public Health Resources by an authorized administrator of DigitalCommons@University of Nebraska - Lincoln. 


\section{Authors}

Mary E. Long, Mary E. Hammons, Joanne L. Davis, B. Christopher Frueh, Myrna M. Khan, Jon D. Elhai, and Ellen J. Teng 


\title{
Imagery rescripting and exposure group treatment of posttraumatic nightmares in Veterans with PTSD
}

\author{
Mary E. Long a,b,c,*, Mary E. Hammons a , Joanne L. Davis ${ }^{\mathrm{d}}$, B. Christopher Frueh ${ }^{\mathrm{b}, \mathrm{e}}$, \\ Myrna M. Khan ${ }^{\mathrm{a}, \mathrm{b}}$, Jon D. Elhai ${ }^{\mathrm{f}}$, Ellen J. Teng ${ }^{\mathrm{a}, \mathrm{b}, \mathrm{c}}$ \\ a Michael E. DeBakey Veterans Affairs Medical Center, 2002 Holcombe Blvd (152), Houston, TX, USA \\ ${ }^{\mathrm{b}}$ Menninger Department of Psychiatry and Behavioral Sciences, Baylor College of Medicine, One Baylor Plaza, Houston, TX, USA

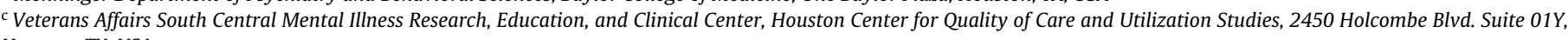 \\ Houston, TX, USA \\ ${ }^{\mathrm{d}}$ Department of Psychology, University of Tulsa, 600 South College, 308G Lorton Hall, Tulsa, OK, USA \\ e Department of Psychology, University of Hawai'i at Hilo, 200 West Kawili St., Hilo, HI, USA \\ ${ }^{\mathrm{f}}$ Department of Psychology, University of Toledo, Mail Stop \#948, 2801W. Bancroft St., Toledo, OH, USA
}

\section{A R T I C L E I N F O}

\section{Article history:}

Received 23 July 2010

Received in revised form 8 December 2010

Accepted 24 December 2010

\section{Keywords:}

PTSD

Imagery rescripting

Nightmares

Veterans

Exposure

\begin{abstract}
A B S T R A C T
This study details results of an open trial of a group psychological treatment for Veterans with posttraumatic stress disorder (PTSD) and chronic posttraumatic nightmares called "Imagery Rescripting and Exposure Therapy" (IRET). IRET is a variant of a successful imagery rescripting treatment for civilian trauma-related nightmares that was modified to address the needs of the Veteran population. Thirtyseven male U.S. Veterans with PTSD and nightmares attended 6 multicomponent group sessions. Findings indicated that the intervention significantly reduced frequency of nightmares and PTSD severity, as well as increased hours of sleep. Unlike the few open trials examining treatment of nightmares in Veterans, effect sizes in this study were similar to those that have been found in the civilian randomized controlled trial. These preliminary findings suggest that a nightmares treatment can be adapted to successfully reduce distress associated with combat Veterans' chronic nightmares. Clinical and research implications are discussed.
\end{abstract}

(C) 2011 Elsevier Ltd. All rights reserved.

\section{Introduction}

Posttraumatic nightmares refer to or replicate traumatic experiences and are considered to be an integral feature of posttraumatic stress disorder (PTSD, Phelps, Forbes, \& Creamer, 2008). Indeed, trauma-related nightmares have been referred to as the hallmark of PTSD due to the frequency with which traumatized individuals report them (Hartmann, 1996). Despite evidence indicating the efficacy of treatments including an imagery technique called imagery rescripting in reducing nightmares and related distress in the civilian population (Wittman, Schredl, \& Kramer, 2006), treatment of nightmares in Veterans has been largely unexamined. The current study investigated the preliminary efficacy of Imagery Rescripting and Exposure Therapy (IRET), a Veteran adaption of a successful civilian imagery rescripting treatment, in reducing symptoms of nightmares and related distress in the Veteran population.

Nightmares in Veterans warrant special attention in the treatment of PTSD because sleep complaints are highly prevalent, have

\footnotetext{
* Corresponding author at: 3266 Green Acres Drive, Bethlehem, PA 18014, USA. Tel.: +1 6102486674 .

E-mail address: melong6@gmail.com (M.E. Long).
}

a generally severe effect on overall functioning, and often persist for decades after the original trauma (Schreuder, Kleeji, \& Rooijmnas, 2000). Reported prevalence rates of chronic nightmares in the Vietnam Veteran population range from 53 to $88 \%$ (Fontana \& Rosenheck, 2008), with approximately $70 \%$ of Operation Enduring Freedom/Operation Iraqi Freedom (OEF/OIF) Veterans diagnosed with PTSD reporting sleep disturbances (Seal, Bertenthal, Miner, Sen, \& Marmar, 2007).

Despite the efficacy of cognitive-behavioral trauma-related therapies in treating global PTSD symptoms, sleep disturbances and nightmares are often resistant to front-line psychological (Galovski, Monson, Bruce, \& Resick, 2009; Spoormaker \& Montgomery, 2008; Zayfert \& DeViva, 2004) and pharmacological (van Liempt, Vermetten, Geuze, \& Westenberg, 2006) treatments of PTSD. Emerging evidence indicates that therapies targeting nightmares directly have been more successful in producing simultaneous improvement in nightmares and related distress than interventions that treat PTSD symptoms globally (Wittman et al., 2006).

Treatment outcome studies incorporating imagery rescripting have evidenced the greatest efficacy for reducing the frequency of nightmares and associated distress in civilians (Long \& Quevillon, 2009; Wittman et al., 2006). During nightmare imagery rescripting treatment, the content of a distressing nightmare is modified to be 
less upsetting, with the rescripted nightmare then being read by the patient directly before going to sleep. According to cognitivebehavioral theorists, imagery rescripting techniques may reduce symptoms of PTSD through activation of the fear network, with exposure to the trauma images and related thoughts and feelings resulting in habituation (Long \& Quevillon, 2009). It has also been hypothesized that imagery rescripting is therapeutic by identifying and modifying maladaptive beliefs, empowering the client through increased mastery over the images, and improving self-soothing abilities and imagery control.

Variants of imagery rescripting interventions have been examined as a treatment for civilians' idiopathic nightmares since the late 1970s (Long \& Quevillon, 2009; Wittman et al., 2006). Davis and Wright (2005) tailored idiopathic imagery rescripting interventions to address the unique characteristics and issues raised by chronic trauma-related nightmares in civilians. In one of the few randomized controlled trials examining the use of imagery rescripting to treat civilian posttraumatic nightmares, the Davis and Wright intervention, Exposure, Relaxation, and Rescripting Therapy (ERRT, 2007), resulted in larger reductions in frequency of nightmares, sleep disturbance, and PSTD frequency at 3-months post-treatment than other imagery rescripting variants (with Cohen's $d$ of .96, 1.04, and .83 , respectively).

To date, most nightmare treatment outcome trials have been conducted only with civilians, with just one randomized and five non-randomized Veteran nightmare studies being published to date (Cook et al., 2010; Forbes et al., 2003; Harb, Cook, Gehrman, Gamble, \& Ross, 2009; Lu, Wagner, Van Male, Whitehead, \& Boehnlein, 2009; Moore \& Krakow, 2007; Nappi, Drummond, Thorp, \& McQuaid, 2010). All studies used imagery rescripting and evidenced reductions in nightmare frequency and related sleep disturbances; however, the studies evidenced smaller effect sizes in these primary outcomes than similar studies with the civilian population (with post-treatment Cohen's $d$ effect sizes ranging from .09 to .70 for nightmare frequency and -.001 to .57 for sleep quantity, and not all differences resulting in a significant $\alpha$ level). Reduction in overall PTSD symptoms was also smaller than in civilian nightmare studies (ranging from .27 to .74 for PTSD frequency); and, unlike the Davis and Wright civilian study (2007), most Veterans retained their PTSD diagnosis after treatment (Lu et al., 2009).

The current study details the findings of an open trial of Imagery Rescripting and Exposure Therapy (IRET). IRET is the first multicomponent group treatment modified from Davis and Wright's (2005) Exposure, Relaxation, and Rescripting Therapy (ERRT) to meet the needs of Veterans with posttraumatic stress disorder (PTSD) and trauma-related nightmares. The hypotheses were that Veteran participation in the IRET treatment would result in a significant improvement in the primary outcome measures (frequency of nightmares and quantity of hours slept), as well as decreases in PTSD frequency, that were similar to the civilian treatment outcome effects.

IRET for Veterans modifies ERRT by increasing the number of sessions, augmenting exposure to the original nightmare, and providing extra practice in nightmare rescripting. These modifications were made in order to address the PSTD treatment-resistance often found in the Veterans (Creamer \& Forbes, 2004), as well as to improve on previous nightmare treatment results with this population. Previous imagery rescripting treatments for Veteran nightmares may not have been as effective as with civilians because of many Veterans' resistance to discuss or modify their nightmares and/or sleep behavior (e.g., due to long-standing negative sleep habits and the frequent long-term, chronic, and replicative nature of their nightmares (Phelps et al., 2008). In order to address this resistance, the number of group treatment sessions was increased from three to six. The lengthier treatment allowed for enhanced focus on sleep management skills, an augmented nightmare exposure component, and extra description and practice of nightmare rescripting. The exposure component of the civilian treatment was augmented in order to capitalize on the effectiveness of exposure therapy in habituating patients to distressing images and related thoughts/feelings (Bisson et al., 2007), and consequently reducing resistance to subsequent discussing and rescripting their nightmares in proceeding sessions.

\section{Method}

\subsection{Participants}

Participants were 37 male Veterans aged between 40 and 72 years who were enrolled in a specialty mental health program for PTSD in a large VA hospital and who completed the IRET group treatment between October 2008 and October 2009. All participants reported a long history of nightmares (i.e., more than 3 decades for the majority of participants), with onset of symptomatology occurring typically during or shortly after returning from deployment. The majority of participants had not participated in PTSD-specific psychosocial interventions prior to entering the group, with PTSD-specific treatment being operationalized as individual or group participation in currently approved front-line psychosocial interventions for Veteran PTSD (e.g., prolonged exposure, cognitive-processing therapy, or anxiety-management skills training). Demographic information for the sample is summarized in Table 1.

Participants were referred to the group treatment by their primary mental health providers and all expressed an interest in participating in psychosocial group treatment for their sleep and nightmare disturbance. All patients received a description and rationale for the treatment by phone by the facilitator and were screened for nightmare frequency, sleep quantity/quality, safety to self and others, active substance dependence or psychosis, and motivation for treatment prior to signing up for the group. Eligible participants were adult Veterans enrolled in the PTSD program reporting at least one combat-related nightmare weekly. Exclusion criteria for the group included patients who were actively suicidal, substance dependent, or psychotic.

\subsection{Measures}

\subsubsection{PTSD Checklist-Military Version (PCL-M) (Weathers, Litz,} Huska, \& Keane, 1994)

The PCL-M is a 17-item Likert-type self-report measure that corresponds to the PTSD criteria in the Diagnostic and Statistical Manual of Mental Disorder-Fourth Edition (DSM-IV) (American Psychiatric and Association, 2000). Participant's completed the PCL-M at the beginning of the first and last sessions in order to assess PTSD frequency at the different time points. The PCL's psychometric properties are compelling, with excellent internal consistency $(\alpha=.94)$ (Blanchard, Jones-Alexander, Buckley, \& Forneris, 1996; Ruggiero, Del Ben, Scotti, \& Rabalais, 2003), and excellent testretest reliability of .88 for a 1 -week interval (Ruggiero et al., 2003). Weathers et al.(1993) found a cutoff score of 50 yielded a sensitivity of .82 and specificity of .83 in a combat Veteran sample.

\subsubsection{Daily sleep activities $\log (D S A L)$ (Thompson, Hamilton, $\mathcal{E}$ West, 1995) \\ The DSAL is a daily diary of 10 -items that assesses quantity of sleep and occurrence of nightmares for the previous night that was adapted for the Veteran IRET open trial. Participants completed the DSAL each morning during the course of the study. Convergent validity of the original DSAL with the Trauma Related Nightmare}


Table 1

Baseline demographics.

\begin{tabular}{|c|c|}
\hline Categorical variables & $n(\%)$ \\
\hline \multicolumn{2}{|l|}{ Gender } \\
\hline Male & $37(100 \%)$ \\
\hline \multicolumn{2}{|l|}{ Ethnicity } \\
\hline African-American & $21(56.8)$ \\
\hline Caucasian & $13(35.1)$ \\
\hline Hispanic & $3(8.1)$ \\
\hline Other (Asian, Native American, Native Hawaiian, Other & $0(0.0)$ \\
\hline Pacific Islander) & \\
\hline \multicolumn{2}{|l|}{ Relationship status } \\
\hline Married & $27(73.0)$ \\
\hline Single & $1(2.7)$ \\
\hline Divorced, separated or widowed & $9(24.3)$ \\
\hline \multicolumn{2}{|l|}{ Education } \\
\hline High School & $15(37.8)$ \\
\hline Some College & $17(45.9)$ \\
\hline College/Post Graduate & $5(13.5)$ \\
\hline \multicolumn{2}{|l|}{ Combat Era } \\
\hline Vietnam & $35(94.6)$ \\
\hline Gulf War & $2(5.4)$ \\
\hline \multicolumn{2}{|l|}{ Current psychological treatment } \\
\hline Medication only & $26(7.03)$ \\
\hline Educational group/support group only & $1(2.7)$ \\
\hline Medication and group & $10(27.0)$ \\
\hline \multicolumn{2}{|l|}{ Received PTSD-specific treatment (prior to IRET) } \\
\hline No previous PTSD-specific treatment & $27(73.0)$ \\
\hline Prolonged exposure (PE) & $1(2.7)$ \\
\hline Cognitive processing therapy (CPT) & $4(10.8)$ \\
\hline Seeking safety & $2(5.4)$ \\
\hline Anxiety management & $3(8.1)$ \\
\hline \multicolumn{2}{|l|}{ Currently prescribed nightmare/sleep medication } \\
\hline Prazosin & $15(40.5)$ \\
\hline Benzodiazepine & $7(18.9)$ \\
\hline \multicolumn{2}{|l|}{ Service connected for PTSD } \\
\hline Yes & $19(51.4)$ \\
\hline No & $18(48.6)$ \\
\hline Continuous variables & $M(S D)$ \\
\hline Age & $62.1(4.1)$ \\
\hline Posttraumatic nightmares (nights/week) & $4.8(1.8)$ \\
\hline Sleep quantity (h/night) & $4.0(1.2)$ \\
\hline PTSD frequency & $68.7(11.1)$ \\
\hline
\end{tabular}

Survey (TRNS, Davis \& Wright, 2001) was found to be adequate in a clinical sample: nights with nightmares $(r=.74-.82)$ and number of nightmares ( $r=.76-.81$ ) (Davis, Byrd, Rhudy, \& Wright, 2007). Weekly frequency of nights with nightmares and average number of hours slept per night over the week, as reported by the participant at the first session and subsequently gathered from the DSAL at the beginning of sessions two through six, are the primary measures of nightmare frequency and sleep hour quantity.

\subsection{Procedure}

\subsubsection{Intervention}

IRET, the six-week multi-component group intervention assessed in the current study, is an adaptation of ERRT modified by the first author for use with the Veteran population. The IRET group intervention consists of six psychotherapy sessions with weekly assigned homework. Based on experience using ERRT with the Veteran population in a clinical setting, IRET lengthened the treatment from three to six sessions in order to augment discussion of cognitive-behavioral skills for sleep management, exposure to the original nightmare (i.e., reading of the written original nightmare daily for one week), and to provide extra practice in nightmare rescripting (i.e., increased time in the fifth session to practice rescripting a nightmare in session).

Specific techniques across the six sessions included: (1) Psychoeducation related to the treatment rationale and the rela- tionship between traumatic events and nightmares, as well as learning and practicing a relaxation exercise each of the first 3 sessions; (2) Psychoeducation regarding the impact of insomnia and cognitive-behavioral skills for sleep management; (3) Review of exposure rationale and exposure to the original nightmare (i.e., writing the most distressing and/or frequent nightmare and reading it several times until anxiety decreases); (4) Review of rationale for imagery rescripting and subsequent modification of the original nightmare around the identified traumatic theme; (5) Continued imagery rescripting, either troubleshooting issues that arose with the original nightmare modification or rescripting a second nightmare; and, (6) Review of skills, relapse prevention planning, and application of skills to future possible nightmares, intrusive imagery, or anxiety-provoking situations. The sessions were conducted weekly for 90 minutes over a 6 -week period and included a review of homework assignments related to the session module content and weekly behavioral assignments. Behavioral assignments included daily monitoring of sleep/nightmare frequency and content, daily practice of relaxation and sleep management skills, daily reading of the original nightmare content to attain habituation, and reading of the rescripted nightmare directly before going to sleep.

\subsubsection{Clinicians}

Group facilitators included the first author, who adapted the intervention, and two Master's level intern clinicians (in separate groups) who were oriented, trained, and supervised by the first author in conjunction with co-author, EJT. Clinicians met weekly during the treatment phase of the intervention to discuss progress and/or any issues that had arisen during session.

\subsubsection{Analyses}

Data was gathered as part of a retrospective chart review, with the study having been approved by the local Institutional and Veteran Affairs Review Boards.

SPSS 17.0 for Windows was used to perform pairwise $t$-test comparisons that were used to compare the sample's pre- to post PCL-M scores. Cohen's $d$ effect size statistics were computed for nightmare frequency, sleep quantity, and PTSD frequency to examine the magnitude of clinical change from sessions 1 to 6 . Cohen's $d$ effect sizes of $.2, .5$, and .8 are regarded as indicating small, medium, and large clinical changes, respectively (Cohen, 1992).

\section{Results}

\subsection{Pre- to post-treatment comparisons}

The univariate analyses revealed that nightmare frequency, sleep quantity, and PCL-M scores all evidenced significant and meaningful improvements over the 6-session IRET group. Of the 33 Veterans present for the last session, 5 Veterans reported no longer having nightmares (15.2\%), 10 reported sleeping an average of 6 hours or more (30.3\%), and 30 (90.9\%) reported at least mild overall improvements in their sleep disturbances (at least 1 less nightmare/week and 1 more hour of sleep/night). Pairwise $t$-test comparisons of the first and last-session PCL-M scores revealed significantly lower scores at the last session $(M=55.7, S D=14.6)$ than at the first session $(M=68.7, S D=11.1), t(32)=7.1, p<.001, d=1.0$ (see Fig. 1 for session-by-session Means). According to the PCL-M Veteran cutoff score of 50,10 Veterans (27\%) also reported no longer meeting the criteria for PTSD after treatment. Effect size analyses demonstrated meaningfully large improvements in nightmare frequency ( $n=29, d=1.37$ ), sleep quantity ( $n=29, d=1.22$ ), and PTSD severity ( $n=33, d=1.0)$, and over this time period. 


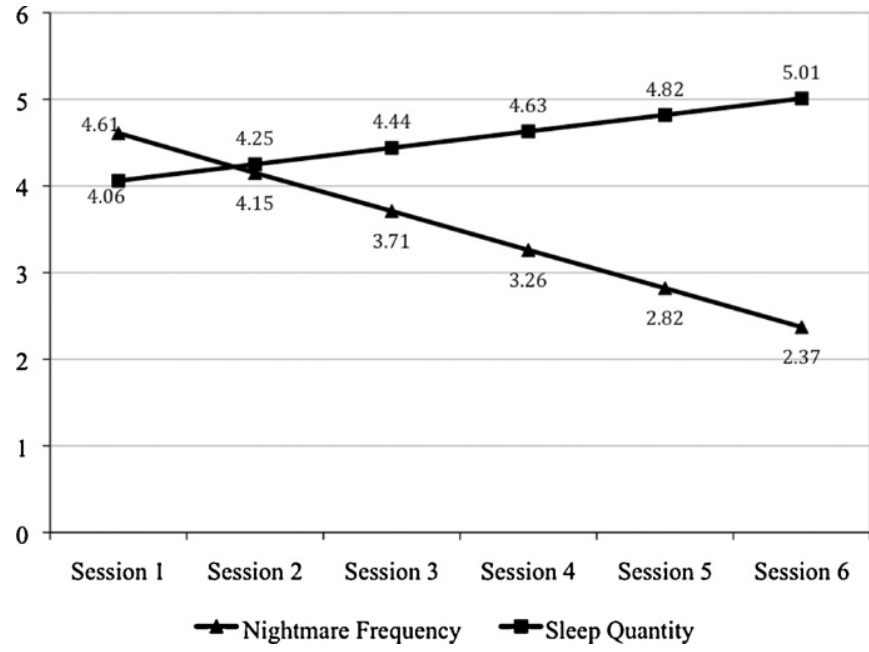

Fig. 1. Estimated nightmare frequency and sleep quantity means across treatment sessions. Nightmare frequency = number of nights with nightmares per week; sleep quantity = average number of nightly hours slept per week.

\section{Discussion}

This study details results of an open trial of Imagery Rescripting and Exposure Therapy (IRET), a multi-component treatment for Veterans with PTSD and trauma-related nightmares. Findings indicated that the intervention reduced frequency of nightmares (from 4.8 /week to $2.4 /$ week), improved quantity of sleep ( $4.0 \mathrm{~h} / \mathrm{night}$ to $5.4 \mathrm{~h} /$ night), and decreased PTSD frequency to a degree that is both statistically significant and clinically meaningful. Unlike previous studies examining imagery rescripting variants in the treatment of Veteran' trauma-related nightmares, the treatment investigated in this study resulted in consistently large effect sizes for all outcome variables that were similar to those that have been found in an RCT with civilian PTSD samples (Davis \& Wright, 2007).

These findings are particularly meaningful given the status of PTSD and nightmare intervention research with the population examined in this study. Previous research has suggested that frontline, trauma-focused cognitive-behavioral interventions have been less clinically effective in reducing global PTSD in Vietnam Veterans than with civilians (Bisson et al., 2007; Creamer \& Forbes, 2004). Given that research indicates that nightmares and other sleep disturbances are particularly resistant to these other-wise successful global PTSD treatments (Galovski et al., 2009; Spoormaker \& Montgomery, 2008; Zayfert \& DeViva, 2004), the implications of significantly and clinically meaningful findings across these domains in a sample comprised primarily of Vietnam Veterans are considerable. These findings are especially note-worthy given that this Vietnam Veteran sample reported to have experienced, like most Veterans of this generation, their posttraumatic stress disorder symptoms and trauma-related nightmares for decades. Also, due to the sample's average age (62.1 years), they also may be susceptible to age-related declines in sleep quantity/quality in a way the younger civilian samples previously studied have not.

The modifications made to Davis and Wright's ERRT in the study's IRET protocol may have accounted for the improved treatment effects over previous nightmare studies with Veterans. IRET modified the civilian ERRT to address many Veterans' resistance to modifying their nightmares and sleep behaviors by lengthening the treatment, which allowed for augmented discussion of cognitive-behavioral skills for sleep management, exposure to the original nightmare, and practice in nightmare rescripting. These modifications capitalize on the effectiveness of exposure therapy in treating symptoms of PTSD through the process of habituation, subsequently reducing the amount of distress caused by the nightmares and increasing the Veterans' willingness and belief that their nightmare images can be modified.

The current study is limited by being an open trial design with no comparison group, moderate sample size with only adequate power for some of the analyses, and may be limited in generalizability because the sample consisted primarily of Vietnam Veterans. Furthermore, despite the sample evidencing meaningfully large degrees of improvements on important nightmare, sleep, and PTSD variables, it was not the full clinical recovery we often seek.

\section{Conclusions}

The current study is timely and relevant because it addresses a gap in the literature regarding the mental health needs of Veterans experiencing the debilitating and potentially treatment-resistant effects of both PTSD and associated nightmares. Based on the positive outcomes from the current study, future research of IRET via randomized controlled trials with long-term follow-up, in a broader range of outcome domains and Veteran war eras is needed and warranted.

\section{Acknowledgements}

This work was supported in part by the Houston VA HSR\&D Center of Excellence (HFP90-020) and the Office of Academic Affiliations, VA Special MIRECC Fellowship Program in Advanced Psychiatry and Psychology, Department of Veterans Affairs. The views expressed in this article are those of the author(s) and do not necessarily represent the views of the Department of Veterans Affairs.

\section{References}

American Psychiatric Association. (2000). Diagnostic and statistical manual of menta disorders (4th, text rev. ed.). Washington, DC: Author.

Bisson, J. I., Ehlers, A., Matthews, R., Pilling, S., Richards, D., \& Turner, S. (2007). Psychological treatments for chronic post-traumatic stress disorders. British Journa of Psychiatry, 190(2), 97-104.

Blanchard, E. B., Jones-Alexander, J., Buckley, T. C., \& Forneris, C. A. (1996). Psychometric properties of the PTSD Checklist (PCL). Behaviour Research and Therapy, 34, 669-673.

Cohen, J. (1992). A power primer. Psychological Bulletin, 112(1), 155-159.

Cook, J. M., Harb, G. C., Gehrman, P. R., Cary, M. S., Gamble, G. M., Forbes, D., et al. (2010). Imagery rehearsal for posttraumatic nightmares: a randomized controlled trial. Journal of Traumatic Stress, 23(5), 553-563.

Creamer, M., \& Forbes, D. (2004). Treatment of posttraumatic stress disorder in military and Veteran populations. Psychotherapy: Theory, Research, Practice, Training, 41(4), 388-398.

Davis, J. L., Byrd, P., Rhudy, J. L., \& Wright, D. C. (2007). Characteristics of chronic nightmares in a trauma-exposed treatment-seeking sample. Dreaming, 17(4) 187-198.

Davis, J. L., \& Wright, D. C. (2001). The Chronic Nightmare Scale. Tulsa, OK: University of Tulsa.

Davis, J. L., \& Wright, D. C. (2005). Case series utilizing exposure, relaxation and rescripting treatment: impact on nightmares, sleep quality, and psychologica distress. Behavioral Sleep Medicine, 3, 151-157.

Davis, J. L., \& Wright, D. C. (2007). Randomized clinical trial for treatment of chronic nightmares in trauma-exposed adults. Journal of Traumatic Stress, 20(2) 123-133.

Fontana, A., \& Rosenheck, R. (2008). Treatment seeking veterans of Iraq and Afghanistan: comparison with veterans of previous wars. Journal of Nervous and Mental Disease, 196, 513-521.

Forbes, D., Phelps, A. J., McHugh, A. F., Debenham, P., Hopwood, M., \& Creamer, M. (2003). Imagery rehearsal in the treatment of posttraumatic nightmares in Australian veterans with chronic combat-related PTSD: 12-month follow-up data. Journal of Traumatic Stress, 16(5), 509-513.

Galovski, T. E., Monson, C., Bruce, S. E., \& Resick, P. A. (2009). Does cognitivebehavioral therapy for PTSD improve perceived health and sleep impairment. Journal of Traumatic Stress, 00(0), 1-8.

Harb, G. C., Cook, J. M., Gehrman, P. R., Gamble, G. M., \& Ross, R. J. (2009). Posttraumatic stress disorder nightmares and sleep disturbance in Iraq war Veterans: a feasible and promising treatment combination. Journal of Aggression, Maltreatment and Trauma, 18(5), 516-531. 
Hartmann, E. (1996). Who develops PTSD nightmares and who doesn't. In D. Barrett (Ed.), Trauma and dreams (pp. 101-113). Cambridge, MA: Harvard University Press.

Long, M. E., \& Quevillon, R. (2009). Imagery rescripting in the treatment of posttraumatic stress disorder. Journal of Cognitive Psychotherapy: an International Quarterly, 23(1), 67-76.

Lu, M., Wagner, A., Van Male, L., Whitehead, A., \& Boehnlein, J. (2009). Imagery rehearsal therapy for posttraumatic nightmares in U.S. Veterans. Journal of Traumatic Stress, 22(3), 236-239.

Moore, B., \& Krakow, B. (2007). Imagery rehearsal therapy for acute posttraumatic nightmares among combat soldiers in Iraq. American Journal of Psychiatry, 164(4), 683-684.

Nappi, C. M., Drummond, S. P., Thorp, S. R., \& McQuaid, J. R. (2010). Effectiveness of imagery rehearsal therapy for the treatment of combat-related nightmares in veterans. Behavior Therapy, 41(2), 237-244.

Phelps, A. J., Forbes, D., \& Creamer, M. (2008). Understanding posttraumatic nightmares: an empirical and conceptual review. Clinical Psychology Review, 28, 338-355.

Ruggiero, K. J., Del Ben, K., Scotti, J. R., \& Rabalais, A. E. (2003). Psychometric properties of the PTSD Checklist-Civilian Version. Journal of Traumatic Stress, 16, 495-502.

Schreuder, B. J., Kleeji, W. C., \& Rooijmnas, H. G. (2000). Nocturnal re-experiencing more than 40 years after war trauma. Journal of Traumatic Stress, 13, 453-463.
Seal, K. H., Bertenthal, D., Miner, C. R., Sen, S., \& Marmar, C. (2007). Bringing the war back home. Archives of Internal Medicine, 167, 476-482.

Spoormaker, V. I., \& Montgomery, P. (2008). Disturbed sleep in post-traumatic stress disorder: secondary symptom or core feature? Sleep Medicine Reviews, 12, 169-184.

Thompson, K. E., Hamilton, M., \& West, J. A. (1995). Group treatment for nightmares in veterans. NCP Clinical Quarterly, 5.(4).

van Liempt, S., Vermetten, E., Geuze, E., \& Westenberg, H. G. (2006). Pharmacotherapy for disordered sleep in post-traumatic stress disorder: a systematic review. International Clinical Psychopharmacology, 21, 193-202.

Weathers, F. W., Litz, B. T., Herman, D. S., Huska, J. A., \& Keane, T. M. (1993). The PTSD checklist: reliability, validity, and diagnostic utility. Paper presented at the annual meeting of the International Society for Traumatic Stress Studies, San Antonio, Texas.

Weathers, F. W., Litz, B. T., Huska, J. A., \& Keane, T. M. (1994). The PTSD ChecklistCivilian Version (PCL-C) for DSM-IV. Boston: National Center for PTSD, Behavioral Sciences Division.

Wittman, L., Schredl, M., \& Kramer, M. (2006). Dreaming in posttraumatic stress disorder: a critical review of phenomenology, psychophysiology and treatment. Psychotherapy and Psychosomatics, 76(1), 25-39.

Zayfert, C., \& DeViva, J. C. (2004). Residual insomnia following cognitive behavioral treatment for PTSD. Journal of Traumatic Stress, 17(1), 69-73. 